\title{
The Influence of Football Training Based on Big Data on Physical Function and Football Skills
}

\author{
Changjun $\mathrm{Hu}^{1}$ and Yang Sun $\mathbb{D}^{2}$ \\ ${ }^{1}$ College of Physical Education, Huazhong University of Science and Technology, Wuhan 430012, Hubei, China \\ ${ }^{2}$ College of Physical Education and Health Sciences, Chongqing Normal University, Chongqing 401331, China
}

Correspondence should be addressed to Yang Sun; corvinus777@163.com

Received 17 September 2021; Revised 26 October 2021; Accepted 19 November 2021; Published 11 January 2022

Academic Editor: omar cheikhrouhou

Copyright $\odot 2022$ Changjun Hu and Yang Sun. This is an open access article distributed under the Creative Commons Attribution License, which permits unrestricted use, distribution, and reproduction in any medium, provided the original work is properly cited.

\begin{abstract}
In order to actively respond to the government's call to scientifically create campus football culture, combine the characteristics of football sports, and improve people's understanding of the mental and intellectual functions of football, this article focuses on the impact of football training on physical function and football technology. Based on the understanding of related theories, the experiment on the impact of football training on physical function and football technology was carried out. The experimental results showed that the weight, height, and BMI increased significantly during the period of football training $(P<0.05)$. The independent sample $T$ test showed that there were no significant differences in height, weight, and BMI between the two groups before and after training; the standing long jump performance of the control group after training showed an upward trend, but the significance level was not statistically significant. Three months later, the time for the experimental team to complete the eightcharacter dribble test in football training was reduced from 20.51 seconds to 15.57 seconds. The independent sample $T$ test found that there was no significant difference in the physical fitness of the two groups before training and the changes in football skills of the subjects before and after training. Then, the clustering algorithm in the big data was used to analyze the data of the experimental group. The standing long jump has the highest performance; the second category belongs to the third level, and the third category belongs to the second level.
\end{abstract}

\section{Introduction}

In recent years, the physique of Chinese adolescents has declined significantly $[1,2]$. Studies have shown that longterm football training can improve intermittent exercise, coordination, and maximum oxygen uptake, as well as physical function and mental health. The high-intensity exercise training in football and the beneficial effects of training are not affected by receptor type, fitness level, or football training experience $[3,4]$. Studies have shown that football training courses tend to show more body movement than other sports (basketball) [5, 6]. Football training can be used as a way to intervene in sports activities to improve the status quo of poor physical fitness. Due to the physiological characteristics of adolescents with low endurance, physical discomfort, and quick recovery, the characteristics of intermittent high-intensity sports in football are also suitable for adolescents $[7,8]$.

For the research on football training, some authors of the research discussed the concept of Chinese football coaches from a theoretical perspective. The concept of coaching includes the theoretical knowledge of sports coaches, the knowledge of combining practice and theory, according to the rules pointed out by the project, characteristics, nature, and trends, clarify the teaching methods and strategies of sports training, and the ultimate goal to be achieved. The above is the understanding of the iterative development process of the training concept, from shallow to deep and from easy to difficult. The development and trend of its changes are closely related to the changes in sports events [9]. Regarding the study of the influence of self-efficacy theory on football players, some researchers analyze its 
practice and application in the football theory of self-efficacy. Research results show that self-efficacy and personal performance are highly correlated. The higher the level of self-performance, the higher the overall personal achievement will be, and the research applies the osmotic training method to the training of high-school football, rearranges the training goals, and reorganizes the football training and training process. With a sense of self-efficacy as the basis and guidance, the theory of football has improved the quality and performance of football training and training process [10]. Some scholars have pointed out when studying football training abroad that European football is relatively developed, and football training is highly valued, and they believe that the content of football training is the actual game scene, and the game also determines its training method, morphology [11]. To sum up, the development of foreign football is relatively fast, mainly for learning football skills in the game, and the training system is relatively mature. Compared with foreign countries, the development of football in our country is relatively slow, and all aspects of resources and conditions are lagging behind developed countries. At present, the research on football is more concentrated on the concept of football coaching, regional football development, talent training, and management mode. Few studies focus on the educational value and psychological impact of football on young people.

This article focuses on the impact of football training on physical function and football technology and analyzes the physical fitness requirements of football sports, the classification of physical functions, and the application of big data on the basis of relevant literature, then conducts an analysis based on these experiments on the influence of football training on physical functions and football skills, and draws relevant conclusions through experiments.

\section{Football Training and Physical Function Research}

\subsection{Physical Fitness Requirements for Football}

(1) The frontcourt players (forwards) are tall and strong, fast in the game, and very agile. They are based on the energy supply characteristics of anaerobic energy supply as the key and aerobic oxidation energy supply [12]. The main task of the frontcourt is to break through the opponent's line of defense, posing a great threat to the opponent's goal. Therefore, athletes need to get rid of their opponents quickly, run fast, and have a strong sense of consciousness. In view of the player's physical characteristics, regular training needs to pay attention to the sensitivity of the player's frontcourt position and adjustment training to improve the player's projection ability and not lose the opportunity to shoot after being expelled. Forwards often accompany enemy defenders when they are running. Whether it is passing, receiving, or dribbling through, possession of the ball directly confronts the defender's body, so in normal training, the player's strength and speed are required.
(2) The midfielder's body has a certain degree of fullness, showing agility, rapid response, and highly developed speed endurance based on aerobic oxidation of energy in the game [13]. The midfielder plays an important role in the game, and the midfield position is also the area where players from both sides play most intensely. Therefore, the midfielder must have a certain degree of physical fullness in order to better fight the opponent in the midfield. Due to the uniqueness and importance of the midfield position, both players pay more attention to the actual control of the midfield. Training requires the player's reaction speed, movement speed, and sensitivity. In the game, the midfielder often has a long distance from the opponent's goal after getting rid of the opponent. In addition to ensuring the general endurance of smooth kicking throughout the game, if the players want to continue to beat the opponent halfway, they also need advanced development speed endurance.

(3) After the athlete is tall and strong, it takes aerobic oxidation and anaerobic energy supply as the key, showing the characteristics of an advanced combination of strength and speed [14]. The tall players in the backcourt provide some protection for the highaltitude ball. Afterwards, the athletes mainly use their physical strength to fight against the opponent's body to strengthen their defense. The main task of the backcourt player is to defend, but he also needs to assist the offense. When the opponent makes a long pass, he has a strong confrontational ability, so the backcourt players should have the ability to accelerate the start instantly and strong confrontational power.

\subsection{Types of Bodily Functions}

(1) Signs related to life such as body shape, weight, blood pressure, breathing rate, and heartbeat, and the overall inspection

(2) Check the body functions of organs including the body functions in various examinations such as hematology test, urine test, electrocardiogram, hearing, vision, and lung function

(3) Check the structure of organs such as chest and abdomen X-rays, upper gastrointestinal tract photos, and ultrasound

2.3. Application of Big Data. Data mining is actually the integration and use of multiple technologies. This is also an interdisciplinary comprehensive research topic that combines database technology, artificial intelligence, machine learning, statistics, knowledge engineering, and object-oriented technologies. With the increase in the amount of control records and network access data, the requirements for complex network applications such as web analysis, decision support, classification, and grouping have become inevitable, and it has become more difficult to maintain a 
complex network environment mainly based on traditional manuals. Data mining technology can directly convert a large amount of data into a source of related information and knowledge and more effectively meet people's needs for analyzing, generalizing, and making full use of the overall characteristics and development trends of data. The grouping analysis technology in data mining technology collects highly similar data in groups based on the measure of similarity. Therefore, data objects in the same cluster can be compared with data objects in different clusters to find the similarity between them. Therefore, data mining technology can be used to group the results of the experimental data, observe the competition performance models of different types of athletes, verify the correlation between physical fitness and competition performance, and provide data reports for the selection of athletes.

\section{Experiment on the Influence of Football Training on Physical Function and Football Technique}

3.1. Experiment Object. Sixty students were randomly selected from the nonphysical education department of ordinary colleges and universities in the city. 44 students were randomly divided into two groups (11 males and 11 females in each group). This group is the experimental group. In addition to participating in university physical education classes, the student also used his free time for three months of experimental training. The other group is the control group which is with free activities and no experimental training in any form except for regular college physical education.

\subsection{Experimental Design}

(1) An electronic scale is used to weigh and measure the height with a tape measure. The height is measured in centimeters $(\mathrm{cm})$, and the weight is measured in kilograms $(\mathrm{kg})$, all accurate to one decimal place. Body mass index (BMI) is currently an indicator used internationally to assess the degree of human obesity. The calculation type is BMI = weight $(\mathrm{kg}) /$ height squared $\left(\mathrm{m}^{2}\right)$.

Electronic sphygmomanometer is used to configure the cuff to measure the quiet blood pressure in $\mathrm{mmHg}$ and $\mathrm{mmHg}$ as the unit.

(2) Athletic ability testing includes physical fitness and technical level testing. Physical fitness testing includes standing long jump, and technical level testing includes quadrant jump with two feet, T-word test, and figure eight dribble test.

(a) The upright vertical jump mainly reflects the explosive power of the atomic lower limbs. Individuals are required to stand naturally behind the jumper, bend their knees, swing their arms in the press, lift their feet forward, and then touch the ground at the same time. When measuring the distance from the front edge of the jumper to the landing point, everyone will try to jump twice and record the farthest score. The recording unit is centimeters, and decimals are not calculated.

(b) Two-foot quadrant jump: 1 meter long and 1 meter wide square is drawn on the ground, the grid is divided into four equal parts, each representing a quadrant, and each quadrant is marked. The test object must be within $15 \mathrm{sec}-$ onds, and the test jumps will be performed in the order of $1 \longrightarrow 2 \longrightarrow 3 \longrightarrow 4 \longrightarrow 1$. The test will not be completed until the end of the 15-second test time. If the tester jumps correctly in the quadrant, points will be awarded. If the tester does not jump correctly, 0.5 points will be deducted and the tester's score will be calculated at the end.

(c) T-word test: four T-shaped marks are placed. To follow the sequence, the object must stay at point A. After starting, the test player needs to start at point $\mathrm{A}$ and then rush to point $\mathrm{B}$. The members of the test team must follow the coach's instructions. The coach's instructions should run to the left. The test team members immediately run to point $\mathrm{D}$ after touching the pointer, then back to point $B$, and then back to point $A$. The coach issues a right-run instruction. The test player must run to point $\mathrm{C}$ immediately after touching the pointer, turn around and return to point $\mathrm{B}$, and then back to point $\mathrm{A}$.

(d) Figure eight dribble test: on the artificial turf field, four marker tubes are used to form a 5meter square. After starting the timer, the subject dribbled the ball forward from the starting point to the diagonal pointer tube and bypassed the diagonal rod, transported back to the lower pointer tube, and then transported the ball into the diagonal pointer tube around the lower pointer tube, and put the pointer tube go around the left and then return to the starting point to complete the test. Record completion time: the shorter the completion time, the higher the level of dribbling. It is completed twice in a row and recorded to get the best result.

(3) Measurement of cardiac structure and function: the test is performed by professional physicians using the LOGIQ BOOK XP series of color digital ultrasonic diagnostic equipment. The test frequency is $2.5 \mathrm{MHz}$, and the subject is in a left position. The size of the heart structure is measured in B and $\mathrm{M}$ modes. Test indicators include left ventricular dilated diameter (LVDD), left ventricular systolic diameter (LVSD), left ventricular volume (LV vol), left ventricular posterior wall thickness in diastole (LVPWD), ventricular diastolic interval (IVTd), and right ventricular dilated diameter (RVDD). Heart pump function is measured in the Doppler mode. Test indicators include left ventricular ejection 
TABLE 1: The influence of football training on body shape.

\begin{tabular}{lcccc}
\hline & & Test group & \multicolumn{2}{c}{ Control group } \\
& Before training & After training & Before training & After training \\
\hline Height $(\mathrm{cm})$ & 165.98 & 168.2 & 166.67 & 168.19 \\
Weight $(\mathrm{kg})$ & 55.11 & 58.4 & 55.17 & 57.12 \\
BMI & 18.45 & 19.17 & 18.61 & 19.43 \\
\hline
\end{tabular}

fraction (LVEF), stroke volume (SV), and isovolumic relaxation time (IVRT).

\subsection{Data Processing}

(1) SPSS22.0 statistical software is used for data analysis, and the results are expressed as mean \pm standard error $(X \pm \mathrm{SEM})$. The independent $T$ test is used to compare the data differences between the experimental group and the control group in the same period, and the Tpair test is used to compare the data differences in the same group of different time periods. The layered grouping method is used to group the fitness level of the experimental group after training. The distance between classes uses the sum of squares of the deviation method, and the distance measurement method uses the sum of squares of the Euclidean distance. After classification, the one-way analysis of variance was used to compare between different study groups. The significant level of difference is $P<0.05$, and the extremely significant level is $P<0.01$.

(2) In the grouping algorithm, the dissimilarity table is an important basis and template for dividing clusters. Therefore, in the grouping algorithm, the data table must be converted into a distinct table. Generally speaking, the distance quantification methods commonly used in grouping algorithms include Minkowski distance, Mahalanobis distance, and cosine distance.

Minkowski distance: it is a measure in the Euclidean space. The distance is expressed as follows:

$$
d_{i j}(q)=\left(\sum_{k=1}^{p}\left|x_{i k}-x_{j k}\right|^{q}\right)^{1 / q} .
$$

For Minkowski distance, $q$ is an important parameter, and the value of $q$ must be greater than zero. If the value of $q$ is 1 , the absolute value of the bright distance is actually called the Hermanton distance. If $q=1$, it is expressed as

$$
d_{i j}(1)=\left(\sum_{k=1}^{p}\left|x_{i k}-x_{j k}\right|\right) \text {. }
$$

\section{Analysis of Experimental Results}

4.1. The Impact of Football Training on Body Shape. Through the experiment, the relevant data about the height and weight of the experimenter before and after the experiment are shown in Table 1.
It can be seen from Figure 1 that during football training, the weight and height of the experimental group and the control group increased significantly $(P<0.05)$. An independent sample $T$ test showed that there were no significant differences in height, weight, or BMI between the two groups before and after training.

4.2. The Impact of Football Training on Blood Pressure and Heartbeat. The relevant data about the blood pressure and heartbeat of the experimenter before and after the experiment obtained through the experiment are shown in Table 2 .

It can be seen from Figure 2 that the diastolic blood pressure of the experimental group and the control group increased significantly $(P<0.01)$, but the systolic blood pressure of the control group increased significantly within 3 months, which was not observed in the experimental group. There was no significant difference in diastolic blood pressure between the two groups within about 3 months after the independent sample $T$ test. After the training period, the average systolic blood pressure of the control group was higher than that of the experimental group, but the heart rate of the experimental group and the control group was significantly different. This is mainly because football is a sport with strong aerobic and anaerobic metabolic conversion and repetitive and intermittent anaerobic endurance. It has fierce competition, high exercise intensity, and long duration. Generally speaking, it will explode in a short time, and the main energy material is ATP-CP. This form of exercise can increase the thickness of the heart muscle, increase the heart's ability to pump blood, and lower the heart rate.

4.3. The Impact of Football Training on Athletic Ability. The relevant data about the exercise ability of the experimenter before and after the experiment obtained through the experiment are shown in Table 3.

It can be seen from Figure 3 that the standing jump performance of the control group showed an upward trend after training, but the significance level was not statistically significant. The independent sample $T$ test found that there was no significant difference in physical fitness between the two groups before training. Three months later, the time for the experimental team to complete the eight-character dribble test in football training was reduced from 20.51 seconds to 15.57 seconds.

4.4. The Influence of Football Training on the Structure and Function of the Heart. The relevant data about the experimenter's heart structure and function before and after the experiment are shown in Table 4. 


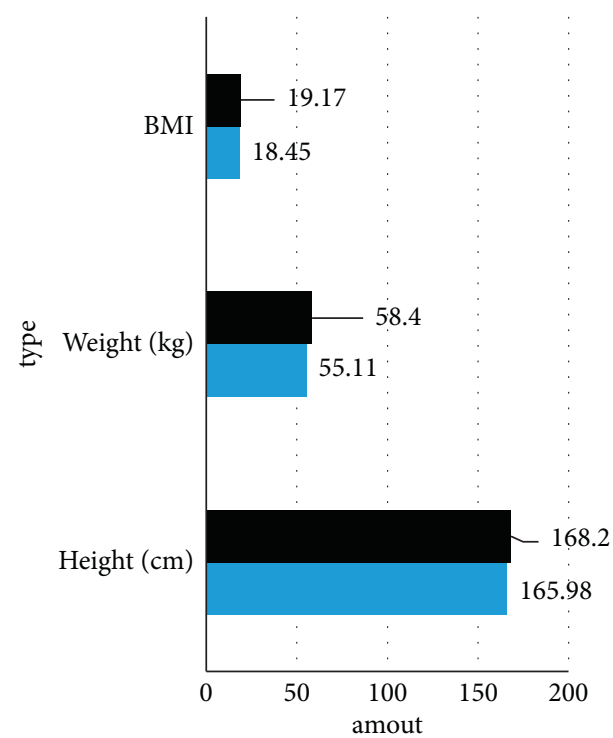

After training

Before training

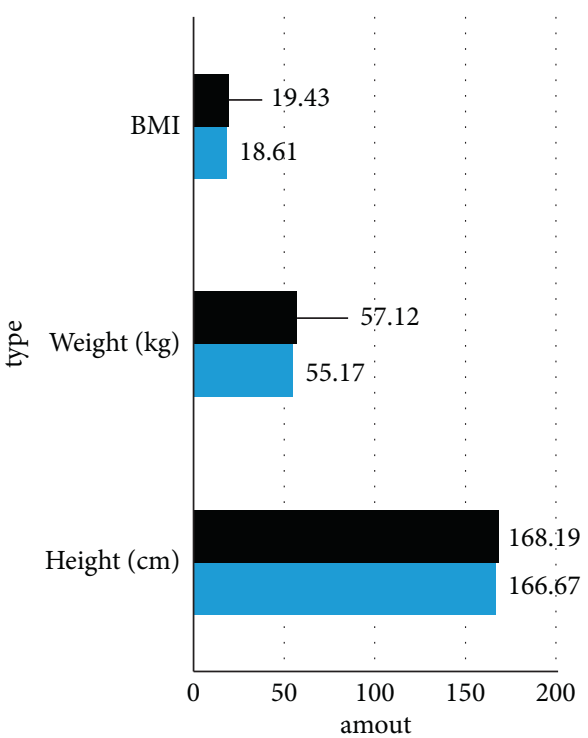

After training

Before training

Figure 1: The influence of football training on body shape.

TABLE 2: The influence of football training on blood pressure and heartbeat.

\begin{tabular}{lcccc}
\hline & \multicolumn{2}{c}{ Test group } & \multicolumn{2}{c}{ Control group } \\
& Before training & After training & Before training & After training \\
\hline Systolic blood pressure $(\mathrm{mmHg})$ & 109.98 & 108.2 & 109.67 & 108.19 \\
Diastolic blood pressure $(\mathrm{mmHg})$ & 82.11 & 85.4 & 83.17 & 85.12 \\
Heart rate (beats/min) & 83 & 78 & 85 & 83 \\
\hline
\end{tabular}
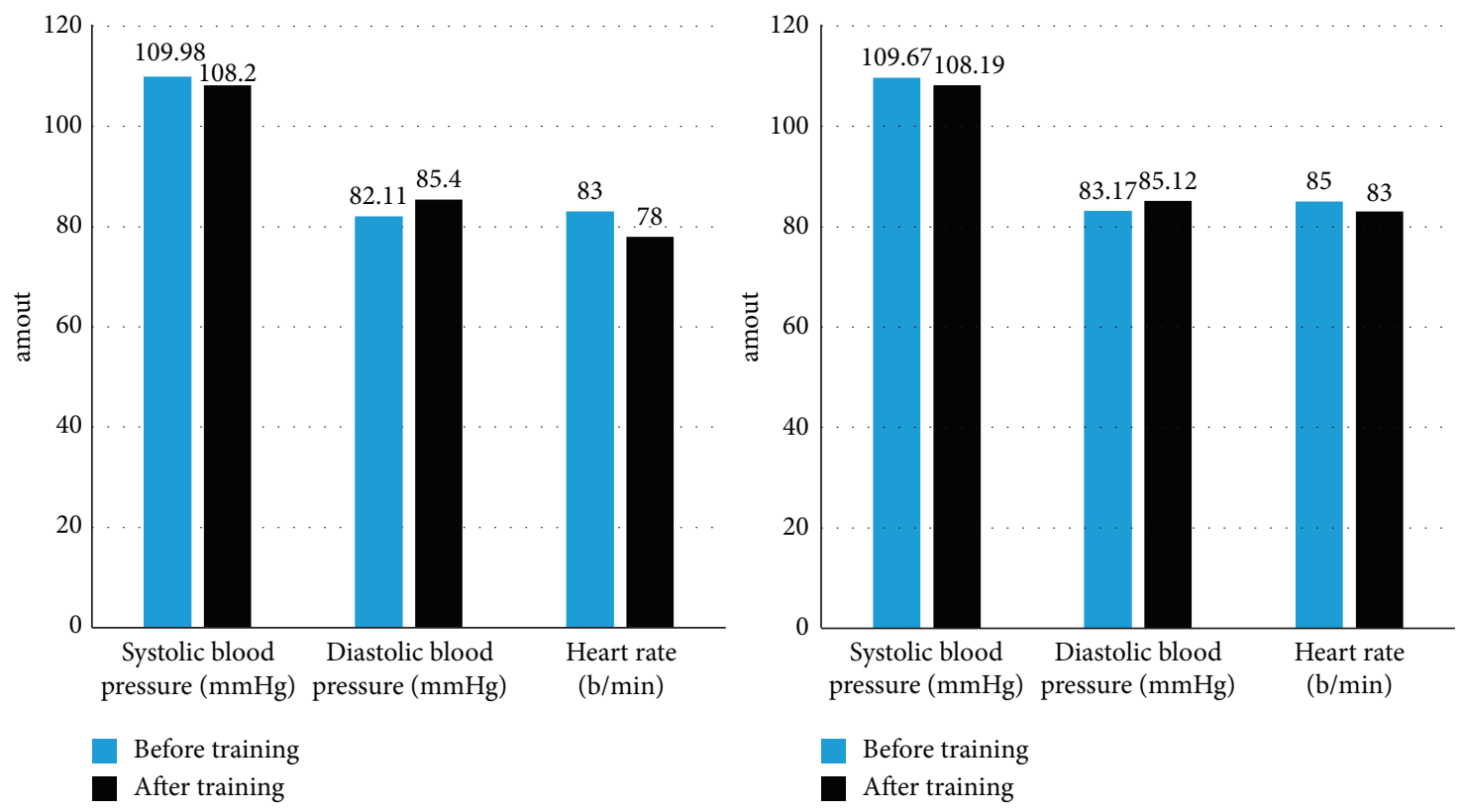

Figure 2: The influence of football training on blood pressure and heartbeat.

It can be seen from Figure 4 that the changes in individual cardiac function indicators, combined with the sample $T$ test, show that this study did not show any significant changes in cardiac function between the experimental group and the control group. The average SV of the experimental group after training was higher than 
TABLE 3: The influence of football training on athletic ability.

\begin{tabular}{lcccc}
\hline & \multicolumn{2}{c}{ Test group } & \multicolumn{2}{c}{ Control group } \\
& Before training & After training & Before training & After training \\
\hline Quadrant jump (s) & 30 & 30 & 30 & 30 \\
T Test & 7.88 & 7.49 & 7.91 & 7.80 \\
Figure eight dribble test $(\mathrm{s})$ & 20.51 & 15.57 & 22.33 & 20.92 \\
Standing long jump $(\mathrm{cm})$ & 16.7 & 16.9 & 16.5 & 17.1 \\
\hline
\end{tabular}

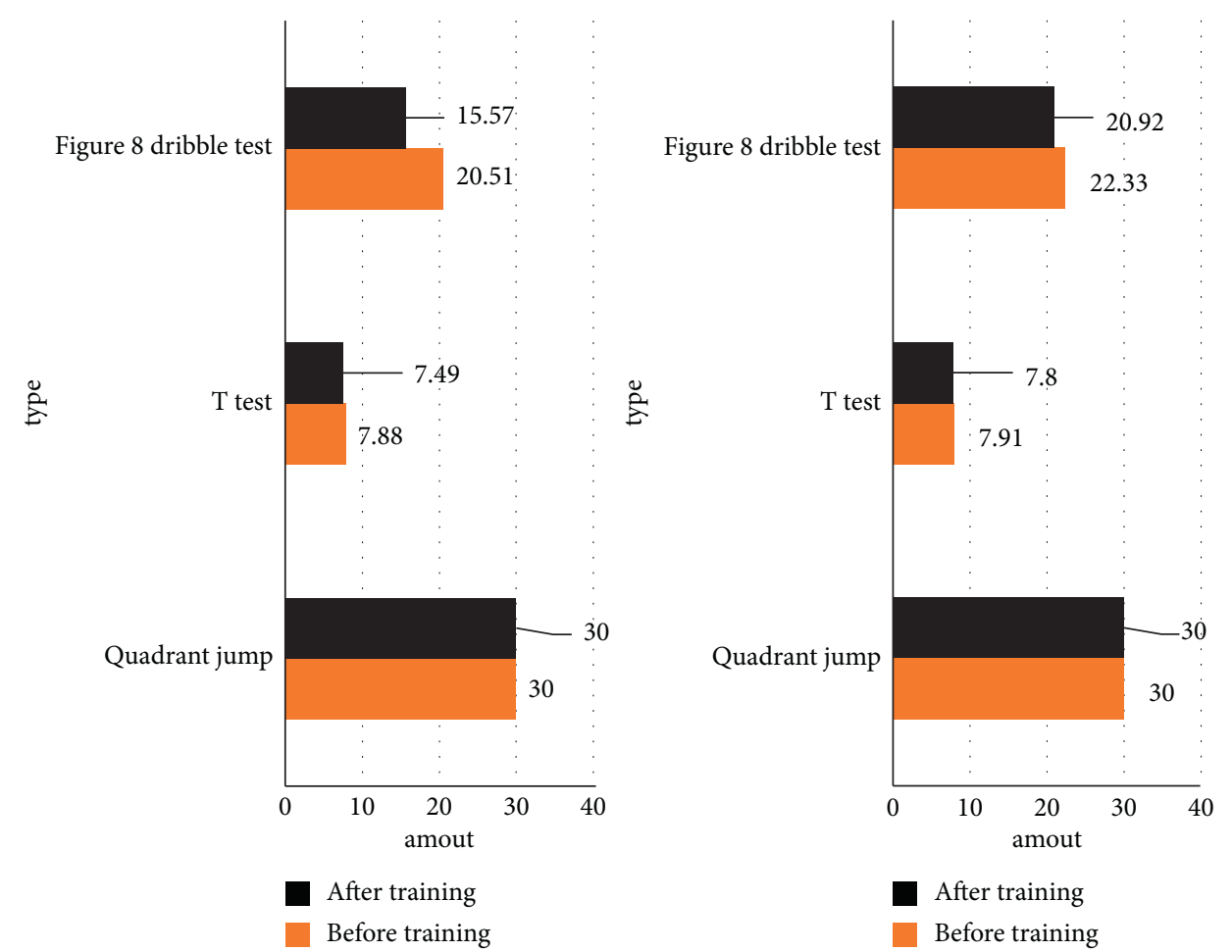

FIgURE 3: The influence of football training on athletic ability.

TABLE 4: The influence of football training on the structure and function of the heart.

\begin{tabular}{lcccc}
\hline & Test group & & \multicolumn{2}{c}{ Control group } \\
& Before training & After training & Before training & 65.82 \\
After training \\
\hline LVEF (\%) & 65.18 & 64.78 & 42.19 & 66.60 \\
SV (ml) & 41.72 & 44.30 & 75.44 & 74.35 \\
IVRT(ms) & 78.76 & 81.23 & & 76.99 \\
\hline
\end{tabular}

that before training, but it was not statistically significant $(P<0.05)$. There was no significant difference between the two teams before and after training.

4.5. Cluster Analysis Results after the Training of the Experimental Group. According to the physical fitness level of the experimental group after training, the individuals were divided into groups to discuss the difference between physical fitness level and sports performance. The results of hierarchical grouping are divided into four categories. There are 7 people in the first category, 8 people in the second category, 13 people in the third category, and 22 people in the fourth category. Subjects in the first category had the highest average level of long jump testing, and compared with the second, third, and fourth categories, there were statistical differences in the long jump test. For the second-class subjects, the standing 

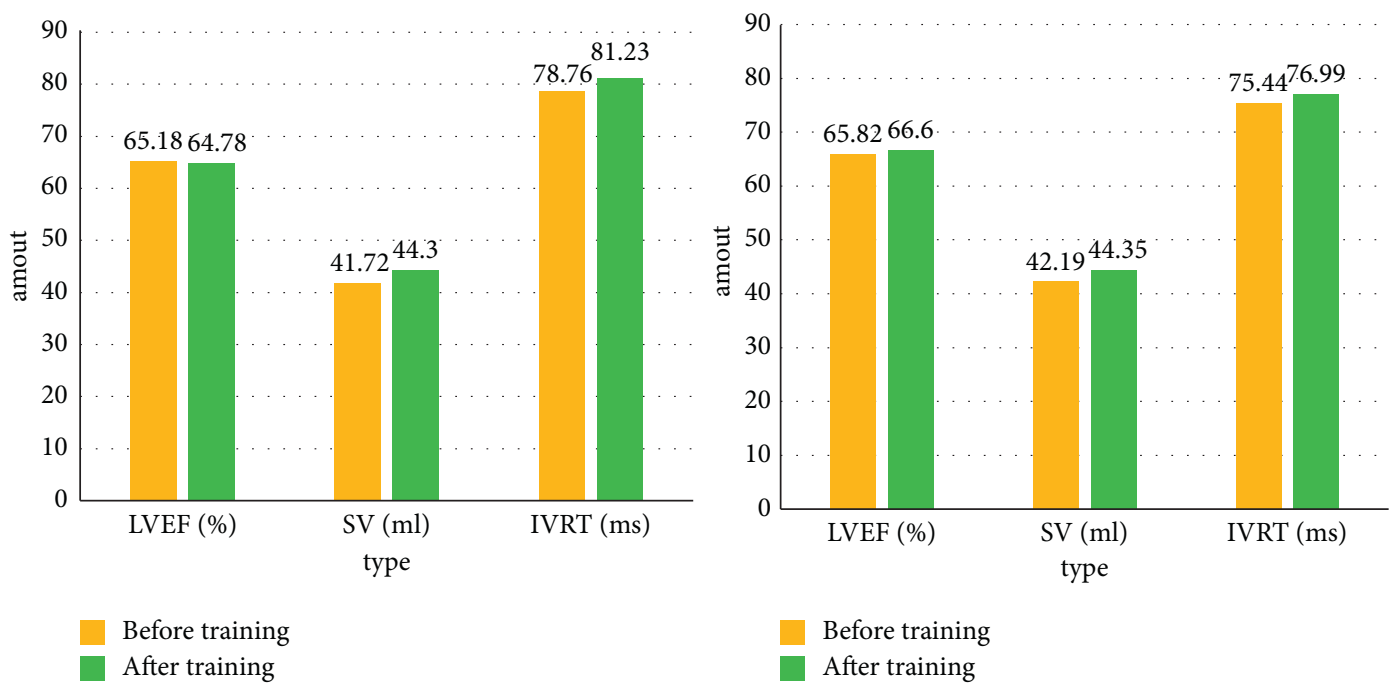

Figure 4: The influence of football training on the structure and function of the heart.

long jump performance is at the third level; for the thirdclass subjects, the standing long jump performance is at the second level.

\section{Conclusions}

This article studies the impact of football training on physical function and football skills. After analyzing the relevant theories, we conducted experiments on the effects of football training on physical functions and football skills. The experimental results showed that the standing jump performance of the control group showed an upward trend after training, but the significance level was not statistically significant. The independent sample $T$ test found that there was no significant difference in the physical fitness of the two groups before training. Then, cluster analysis of the experimental group training experiment results was used to obtain the highest average standing long jump level test of subjects in the first category, compared with the standing long jump test. There are statistical differences between the second, third, and fourth categories. For the second-class subjects, the standing long jump performance is at the third level; for the third-class subjects, the standing long jump performance is at the second level. However, there are certain limitations in the research process, and there is no research on the performance of the game.

\section{Data Availability}

The data underlying the results presented in the study are available within the article.

\section{Conflicts of Interest}

The authors declare that there are no potential conflicts of interest.

\section{References}

[1] C. Ikeda, S. Nakajima, T. Ohyanagi, Y. Nakamura, and Y. Sengoku, "The influence of physical function on drawing performance and drawing motion in clumsy children," Asian Journal of Occupational Therapy, vol. 15, no. 1, pp. 37-44, 2019.

[2] P. A. Ward, S. Ramsden, A. J. Coutts, A. T. Hulton, and B. Drust, "Positional differences in running and nonrunning activities during elite american football training," The Journal of Strength \& Conditioning Research, vol. 32, no. 7, pp. 2072-2084, 2018.

[3] S. Y. Hong, "Effects of periodic multicomponent exercise training and de-training for 18 months on physical function in older adults with dementia," Alzheimer's and Dementia, vol. 14, no. 7, pp. P558-P559, 2018.

[4] M. F. F. Mediano, E. S. Leifer, L. S. Cooper et al., "Influence of baseline physical activity level on exercise training response and clinical outcomes in heart failure: the HF-action trial," Journal of the American College of Cardiology: Heart Failure, vol. 6, no. 12, pp. 1011-1019, 2018.

[5] G. A. Gelade, "The influence of team composition on attacking and defending in football," Journal of Sports Economics, vol. 19, no. 8, pp. 1174-1190, 2018.

[6] J. Eslami, C. Walbert, A.-L. Beaucour, A. Bourges, and A. Noumowe, "Influence of physical and mechanical properties on the durability of limestone subjected to freeze-thaw cycles," Construction and Building Materials, vol. 162, no. 20, pp. 420-429, 2018.

[7] A. N. Szabo-Reed, E. A. Willis, J. Lee, C. H. Hillman, R. A. Washburn, and J. E. Donnelly, "The influence of classroom physical activity participation and time on task on academic achievement," Translational Journal of the ACSM, vol. 4, no. 12, pp. 84-95, 2019.

[8] E. Sundstrup, M. D. Jakobsen, L. L. Andersen et al., "Positive effects of 1-year football and strength training on mechanical muscle function and functional capacity in elderly men," European Journal of Applied Physiology, vol. 116, no. 6, pp. 1127-1138, 2016.

[9] A. Mancini, D. Vitucci, G. Labruna et al., "Effect of lifelong football training on the expression of muscle molecular 
markers involved in healthy longevity," European Journal of Applied Physiology, vol. 117, no. 4, pp. 721-730, 2017.

[10] C. Zhu, "Applying edge computing to analyse path planning algorithm in college football training," International Journal of System Assurance Engineering and Management, vol. 12, no. 4, pp. 844-852, 2021.

[11] J. Uth, B. Fristrup, V. Sørensen et al., "Exercise intensity and cardiovascular health outcomes after 12 months of football fitness training in women treated for stage I-III breast cancer: results from the football fitness after Breast Cancer (ABC) randomized controlled trial," Progress in Cardiovascular Diseases, vol. 63, no. 6, pp. 792-799, 2020.

[12] J. Ekstrand, M. Waldén, and M. Hägglund, "Hamstring injuries have increased by $4 \%$ annually in men's professional football, since 2001: a 13-year longitudinal analysis of the UEFA Elite Club injury study," British Journal of Sports Medicine, vol. 50, no. 12, pp. 731-737, 2016.

[13] K. Aden, E. Nathan, and S. Michael, "Incorporating perceptual decision-making training into high-intensity interval training for Australian football umpires," Journal of Sports Sciences, vol. 37, pp. 1-7, 2018.

[14] S. Anderson, "NCAA football off-season training: unanswered prayers. A prayer answered," Journal of Athletic Training, vol. 52, no. 2, pp. 145-148, 2017. 